\title{
New controlled release material: aerated egg white gels induced by calcium ions
}

\author{
Marta Tomczyńska-Mleko ${ }^{1}$ Akihiro Handa ${ }^{2}$ - Marta Wesołowska-Trojanowska ${ }^{3}$. \\ Konrad Terpiłowski ${ }^{4} \cdot$ Cezary Kwiatkowski $^{5} \cdot$ Stanisław Mleko $^{6}$
}

Received: 13 October 2015 / Revised: 11 December 2015 / Accepted: 24 December 2015 / Published online: 7 January 2016 (C) The Author(s) 2016. This article is published with open access at Springerlink.com

\begin{abstract}
The aim of the research was to use low-mineral egg white albumin isolate to obtain aerated calcium ioninduced gels and to investigate their aptitude as matrices for active ingredients release. Aerated gels were prepared by adding calcium ions to pre-heated protein dispersions with simultaneous aeration. $20 \mathrm{mM}$ calcium concentration was an optimal concentration at which the maximum viscosity and hardness of the gels were found. For higher concentrations of calcium ions $(25-30 \mathrm{mM})$, aerated gels were characterized by lower values of the moduli and tangent of the phase angle was larger for aerated gels which indicated more viscous character than that of non-aerated gels. Increased ions concentration causes higher aggregation of protein matrix and less smooth microstructure of the interface between the gel and air. An increase in calcium concentration from 5 to $30 \mathrm{mM}$ caused an increase in an average bubble size. The release of calcium ions from aerated gels was measured in an artificial stomach. It occurred
\end{abstract}

Stanisław Mleko

dairywhey@tlen.pl

Marta Tomczyńska-Mleko

martamleko@tlen.pl

Akihiro Handa

akihiro_handa@kewpie.co.jp

Marta Wesołowska-Trojanowska

marta.wesolowska-trojanowska@up.lublin.pl

Konrad Terpiłowski

terpil@ poczta.umcs.lublin.pl

Cezary Kwiatkowski

czarkw@poczta.onet.pl

1 Institute of Plant Genetics, Breeding and Biotechnology,

University of Life Sciences in Lublin, Akademicka Street 15,

20-950 Lublin, Poland by Fickian diffusion through the swelling matrix and it was faster for the gels with higher concentration of calcium. An increase in calcium concentration caused an increase in surface roughness of the aerated gels. There were linear correlations between the quadratic mean of the surface roughness and " $n$ " coefficient from the Ritger and Peppas equation and between the maximum roughness size and " $n$ ". The increased calcium concentration made the gel microstructure more particulate and the surface rougher, which enabled faster proteolysis of the gel in an artificial stomach and faster diffusion of calcium ions.

Keywords Aerated $\cdot$ Egg white $\cdot$ Gel $\cdot$ Release $\cdot$ Microstructure $\cdot$ Surface properties $\cdot$ Rheology

2 R\&D Division, Institute of Technology, Kewpie Corporation, 2-5-7 Sengawa-cho, Chofu-shi, Tokyo, Japan

3 Department of Biotechnology, Human Nutrition and Food Commodity Science, University of Life Sciences, Skromna 8, 20-704 Lublin, Poland

4 Department of Physical Chemistry-Interfacial Phenomena, Maria Curie Skłodowska University, M. Curie Skłodowska Sq. 3, 20-031 Lublin, Poland

5 Department of Herbology and Plant Cultivation Techniques, University of Life Sciences, Akademicka 13, 20-950 Lublin, Poland

6 Department of Milk Technology and Hydrocolloids, University of Life Sciences in Lublin, Skromna 8, 20-704 Lublin, Poland 


\section{Introduction}

Proteins of animal origin should be the main source of amino acids in human diet. Chicken egg protein is treated as a reference protein. Egg white has a protein content of about $11 \%$ and comprises about $58 \%$ of the entire egg mass [1]. The main proteins of egg white are ovalbumin, ovotransferrin, ovomucoid, globulins and lysozyme. Egg white protein has excellent functional properties and among them, the most important are: gelation, foaming and emulsification. Along with high nutritional value, it is a very important substrate for food industry.

In recent years, the research on new carriers for drugs and nutraceutics release [2] has been in intensive. In order to release the active substance, there are used the following mechanisms: swelling, diffusion and the effect of $\mathrm{pH}$ or temperature [3]. Natural hydrocolloids have the advantage over chemically synthesized polymers, as the former are biocompatible and harmless for human organisms [4]. Lately egg white albumen gel has provided a medium to deliver nutrients and flavors [5]. Gels can be subcutaneously implanted in the body and then no re-cutting the skin is needed as the gel gradually degrades in the organisms [6]. Lately a gel with anti-cancer active substance has been formed to heal breast and cervical cancer [7]. Because of short half-life of many drugs, several doses per day must be administered. Aeration of the gel could create a matrix which floating in the stomach would increase the release time. This is important especially for treatment of gastric infections caused e.g., by the bacterium Helicobacter pylori, which is responsible for stomach inflammation and ulcers. Rajinikanth and Mishra [8] obtained gassed gels using calcium carbonate. The process was performed on acidic $\mathrm{pH}$. In the previous study, aerated whey protein gels were obtained by the cold gelation process conducted simultaneously with the aeration [9]. No $\mathrm{pH}$ restriction is applied under these process conditions. TomczyńskaMleko and Mleko [10] used aerated whey protein gels as an active matrix for the release of different ions in an artificial stomach.

Heating of protein in low ionic strength dispersion converts it to the denatured form, and this is a preliminary stage for obtaining room temperature set gels. Univalent nature of protein molecule surfaces prevents interactions and promotes repulsive forces. After cooling down the dispersion, the next steps involve neutralization of univalent charges on the protein molecule surfaces. This can be achieved by the addition of salts or acids. This process is called the "screening effect" as oppositely charged ions form a shield around protein molecules. The first step involves largely formation of disulfide bonds and exposure of hydrophobic amino acid residues $[11,12]$. In the second step, in the case of multivalent ions, not only a screening effect is observed but formation of intermolecular ion bridges between the charged carboxylic groups of protein occurs [13]. Gel maturation at storage causes large increase in elasticity which results from formation of multiple hydrogen bonds [5]. Many investigations on cold gelation process of whey protein are reported [1416]. It is difficult to perform cold gelation of egg white protein, as commercial isolates and concentrates contain too high concentrations of salts and they form a gel in the preheating stage of the process $[17,18]$. Even at very low protein concentration ( $3 \%$ ), a turbid gel is formed. Lately Kewpie Corporation has produced a new low-mineral egg white isolate. Based on this product, $\mathrm{Ca}$-induced egg white protein gels with a various microstructure were obtained [19].

The aim of the research was to use the isolates to obtain aerated calcium ion-induced gels and to investigate their aptitude as matrices for active ingredients release.

\section{Materials and methods}

\section{Materials}

The material was egg white albumin "low mineral, high gel type" (88.1\% protein) (Kewpie Corporation, Tokyo, Japan). Protein and fat concentrations were determined by the Kjeldahl and the Soxhlet method, accordingly. Mineral analysis of the isolate was performed by a flame atomization atomic absorption spectrometry using a Varian SpectrAA 280 atomic absorption spectrometer equipped with a GTA graphite furnace, Zeeman background correction, and a $4.0 \mathrm{~mA} \mathrm{Mg}$ hollow cathode lamp (Varian, Inc., Palo Alto, USA) (Table 1). The samples were dissolved in a $1 \%$ aqueous solution of nitric acid [20]. Throughout the analysis for all analysis, the analytical line at $202.6 \mathrm{~nm}$ was used. As the inert transport gas argon was applied for all analyses. Measurements were taken on $10 \mu 1$ samples using pyrolytical-coated graphite tubes.

\section{Preparation of the aerated egg white protein isolate gels}

Egg white protein isolate (EWPI) dispersion $6 \%(\mathrm{w} / \mathrm{w})$ was made by hydrating in distilled water. The above protein concentration was selected based on the preliminary research on sensorially observed ability of EWPI gels to hold air bubbles. Protein dispersion was heated in water bath for $30 \mathrm{~min}$ at $80{ }^{\circ} \mathrm{C}$ and after heating it was cooled down immediately. Calcium chloride was added to obtain $5,10,15,20,25$ or $30 \mathrm{mM} \mathrm{Ca}^{2+}$ concentration. After adding the salt, solutions were foamed for $30 \mathrm{~s}$ at $600 \mathrm{rpm}$ 
Table 1 Composition of egg white albumin isolate (low mineral (high gel type)—Kewpie Corporation, Tokyo, Japan)

\begin{tabular}{llllllll}
\hline Protein $(\%) n \times 6.00$ & Fat $(\%)$ & $\mathrm{Ca}(\mathrm{mg} / \mathrm{kg})$ & $\mathrm{Mg}(\mathrm{mg} / \mathrm{kg})$ & $\mathrm{Na}(\mathrm{g} / \mathrm{kg})$ & $\mathrm{K}(\mathrm{g} / \mathrm{kg})$ & $\mathrm{Zn}(\mathrm{mg} / \mathrm{kg})$ & $\mathrm{Cu}(\mathrm{mg} / \mathrm{kg})$ \\
\hline $88.1+0.6$ & $<0.1$ & $198+11$ & $214+19$ & $1.57+0.09$ & $1.59+0.06$ & $3.78+1.47$ & $<2.6$ \\
\hline
\end{tabular}

using a RW 11B mixer (IKA, Staufen, Germany). Aerated gels were stored for $20 \mathrm{~h}$ at $7{ }^{\circ} \mathrm{C}$, equilibrated at $21^{\circ} \mathrm{C}$ for $1 \mathrm{~h}$ and subjected to determination of their properties.

\section{Viscosity measurements using an ultrasound viscometer}

Viscosity $\times$ density in mPas $\times \mathrm{g} / \mathrm{cm}^{3}$ of the aerated gels was measured using a Unipan type 505 ultrasound viscometer (UNIPAN, Warsaw, Poland). Six measurements were taken for each test, and the mean was calculated.

\section{Puncture test}

Puncture tests were performed with a TA-XT2i Texture Analyser (Stable Micro Systems, Godalming, UK). The aerated and non-foamed gel samples were analyzed by puncture test using the 10-mm-diameter steel cylinder probe. The probe was plunged into gels with $1.0 \mathrm{~mm} / \mathrm{s}$ speed for $30 \mathrm{~s}$. The gels were obtained in $50 \mathrm{~mm}$ diameter beakers to avoid the edge effect. Hardness of the samples was measured as the maximal force of penetration. Six measurements were made for each test, and the mean was calculated.

\section{Oscillatory rheology}

Dynamic oscillatory measurements were performed using a RS300 (ThermoHaake, Karlsruhe, Germany) rheometer with a serrated parallel steel plate geometry $(35 \mathrm{~mm}$ diameter) to limit the potentiality of sliding effects. The gel samples ( $35 \mathrm{~mm}$ diameter and $3 \mathrm{~mm}$ thick) were cut using a scalpel and analyzed by strain and frequency sweep. For the strain sweeps, a frequency of $0.1 \mathrm{~Hz}$ was used and for the frequency sweep a $0.1-10 \mathrm{~Hz}$ range was used at 0.01 strain. All the measurements were taken in the linear viscoelastic range, determined by the strain sweep.

\section{Scanning electron microscopy (SEM)}

The samples of the aerated gels were fixed by immersion in the $2.5 \%$ glutaraldehyde solution in the $0.1 \mathrm{M}$ sodium cacodylate buffer. The samples were dehydrated in serial dilutions of ethanol and acetone and dried at the critical point in liquid carbon dioxide. The preparations were coated with gold using a vacuum evaporator EMITECH K550x (Emitech, Ashford, United Kingdom). The preparations were viewed and photographed using a scanning electron microscope VEGA II LMU (Tescan, Canberra, USA).

\section{Turbiscan apparatus measurements of average bubble size}

The average bubble size of the aerated gels was investigated by Turbiscan apparatus (Formulaction, L'Union, France). The aerated gels were carefully transferred to a flat-bottomed glass cylindrical sample cell. The aerated gel samples were scanned for $5 \min 7{ }^{\circ} \mathrm{C}$. The samples were scanned by a pulsed near infrared light source (wavelength $880 \mathrm{~nm}$ ), and two synchronized detectors were used to collect the transmitted and backscattering lights. The obtained data were expressed as a percentage intensity of the transmission or backscattering. The average size of the air bubbles dispersed in the gel was calculated using the Turbiscan Lab expert software (Formulaction, L'Union, France). All measurements were made in triplicate, and the presented results are the arithmetic means.

\section{Surface roughness}

Gels surface was observed using an optical profilometer GT Contour Surface Metrology (Veeco, Tucson, USA). Surface roughness was determined using the Vision64 computer program (Veeco, Tucson, USA).

\section{Digestion of the gels in an artificial stomach}

The gels and aerated gels were cut into $10 \mathrm{~mm}$ edge cubes using a surgery scalpel. Approximately $15 \mathrm{~g}$ batch of each sample was used for artificial stomach. The sample was placed in an artificial stomach constructed at the Department of Biotechnology, Human Nutrition and Food Commodity Science, University of Life Sciences in Lublin, Poland. Artificial stomach consisted of a $1,000 \mathrm{~cm}^{3}$ cylindrical bioreactor (Schott glass, $15 \mathrm{~cm}$ in diameter) with a heating mantle, magnetic stirrer, automatic $\mathrm{pH}$ control system and a water bath. The bioreactor was filled with $500 \mathrm{~cm}^{3}$ of hydrochloric acid solution at $\mathrm{pH} 2.3$ and $1.6 \mathrm{~g}$ of pepsin from the porcine stomach mucosa $(2000 \mathrm{U} / \mathrm{mg}$ protein, Sigma-Aldrich, St. Louis, USA) was added. Gels and aerated gels hydrolysis process was carried out for $10 \mathrm{~h}$ in automatically controlled $\mathrm{pH} 2.3$ and a temperature of $37^{\circ} \mathrm{C}$. The samples of the artificial stomach liquid were taken for analysis every $5 \mathrm{~min}$. In order to investigate the impact of the solution at $\mathrm{pH} 2.3$ on the cations release, similar experiments were carried out without the addition of the pepsin. The calcium content in the samples was 
determined by an atomic absorption spectrometry using a Varian Spectra 280 FS (Varian, Inc., Palo Alto, USA). The presented charts are the average of three replications, and they were fitted to the power law model.

\section{Statistical analysis}

Statistical analysis of the results (standard deviation, analysis of variance) was performed using the statistical program STATISTICA 5.0 PL (StatSoft Polska, Warsaw, Poland). The significance of differences between means was determined using the Tukey's test at the confidence level of $p \leq 0.05$ based on the least significant difference.

\section{Results and discussion}

\section{Ultrasound viscosity and puncture test}

Figure 1 presents the influence of calcium concentration on dynamic viscosity $\mathrm{x}$ density measured by an ultrasound viscometer (white) and hardness (gray) of the aerated gels measured by a puncture test. There is an optimal concentration of the ions, at which there is the highest value of viscosity and hardness. The increased calcium concentration creates gels with higher hardness and viscosity [19]. Similar tendencies observed for calcium ions were observed for other ions. da Silva et al. [21] noted for the whey protein gels that puncture resistance increased with the increasing $\mathrm{Mg}^{2+}$ concentration. Gels microstructure is destroyed in the aeration process, and the re-healing process must take place to obtain a three-dimensional gel matrix. Probably the structure of the gels induced above $20 \mathrm{mM}$ calcium concentration is too strong, and they do not re-heal after the structure damage caused by aeration. Globular proteins physical gels have an ability to rebuild their structure when the shear forces are removed but when the interactions between the protein molecules are too strong, it is very difficult for the disrupted gel to rebuild [22]. On the other hands, low ion concentrations induce too weak gels and formed air bubbles are not stable having a tendency to move to the surface of the gel (picture not shown).

\section{Oscillatory rheology}

Figure 2 presents the frequency sweep of gels induced by different calcium ions concentrations. For higher concentrations of calcium ions, larger increase in storage $\left(\mathrm{G}^{\prime}\right)$ and loss moduli $\left(\mathrm{G}^{\prime \prime}\right)$ was observed. Higher concentration of calcium ion-induced stronger gels as aggregation of the pre-heated EWPI increased. For all samples, the storage modulus value was several times higher than the loss modulus, indicating that the samples were weak gels. Very interesting behavior was observed when non-aerated gels were compared with the aerated ones (Fig. 2a-1). For low calcium concentration ( 5 and $10 \mathrm{mM}$ ), values of the moduli were larger for the aerated than non-aerated gels, but tangent of the phase angle was larger for the aerated ones (Fig. 2a-d). The $\tan \delta$ values of the gels were lower than 1 over the whole frequency range, indicating the elastic behavior of the samples [23]. The structure of aerated gels was a little firmer than that of the non-aerated ones, but the aerated gels were more viscous and less elastic materials than the non-aerated ones. Loss in elasticity could be caused by an aeration process with air bubbles as weak points in the elastic matrix of the gel. At $15 \mathrm{mM}$ calcium ion concentration, there were the same values of the moduli for the non-aerated and aerated gels (Fig. 2e) and the aerated gels were more viscous and less elastic than the nonaerated ones (Fig. 2f). For $20 \mathrm{mM}$ calcium ions, the tangent of the phase angle was larger for non-aerated gels (Fig. 2h) which indicates more elastic nature of the aerated gels. Ultrasound viscosity and puncture test hardness showed that $20 \mathrm{mM}$ calcium ions is an optimal concentration for
Fig. 1 Influence of calcium concentration on dynamic viscosity $\times$ density measured by an ultrasound viscometer (white) and hardness (gray) measured by a puncture test for aerated egg white gels

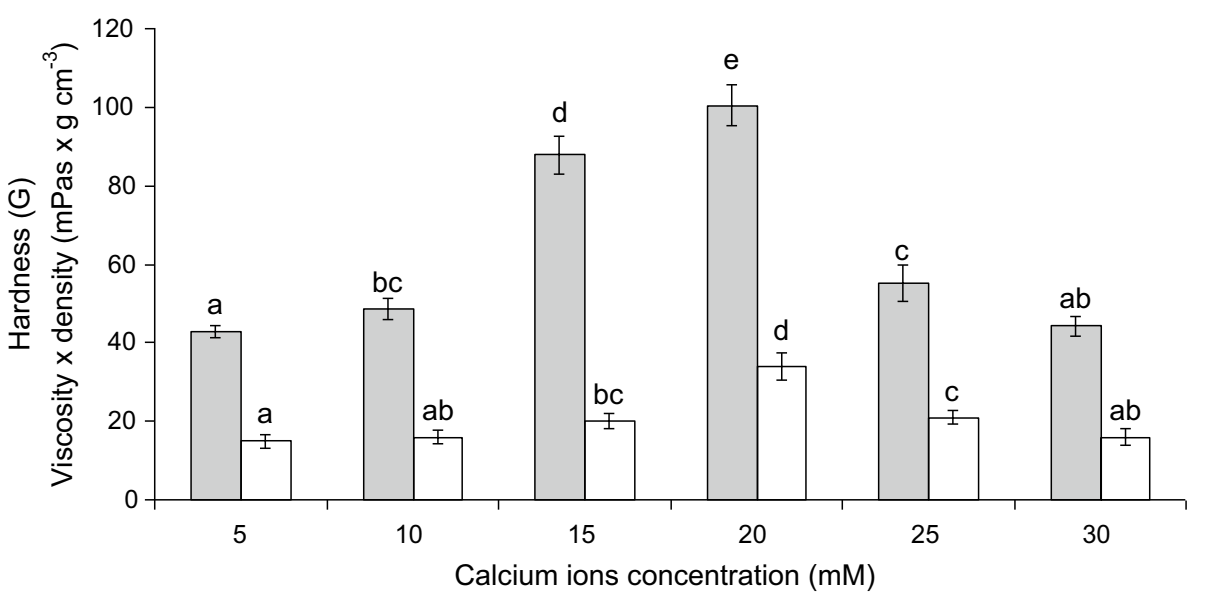


Fig. 2 Changes of (storage modulus $\mathrm{G}^{\prime}$ and loss modulus $\mathrm{G}^{\prime \prime}$, tangent $\delta$ ) with the frequency for gels and aerated gels induced by $5 \mathrm{mM}(\mathbf{a}, \mathbf{b}) 10 \mathrm{mM}$ (c, d) $15 \mathrm{mM}(\mathbf{e}, \mathbf{f}) 20 \mathrm{mM}(\mathbf{g}$, h) $25 \mathrm{mM}(\mathbf{i}, \mathbf{j}) 30 \mathrm{mM}(\mathbf{k}, \mathbf{l})$ calcium ions concentration
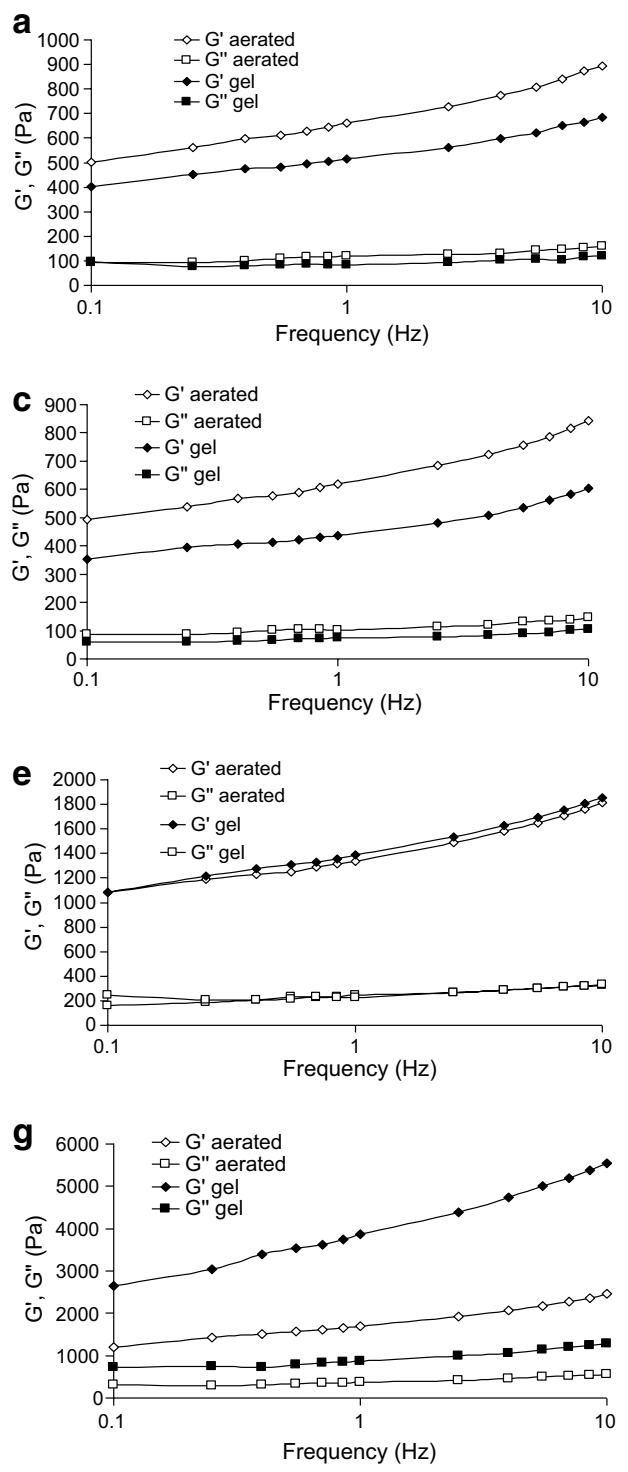

i
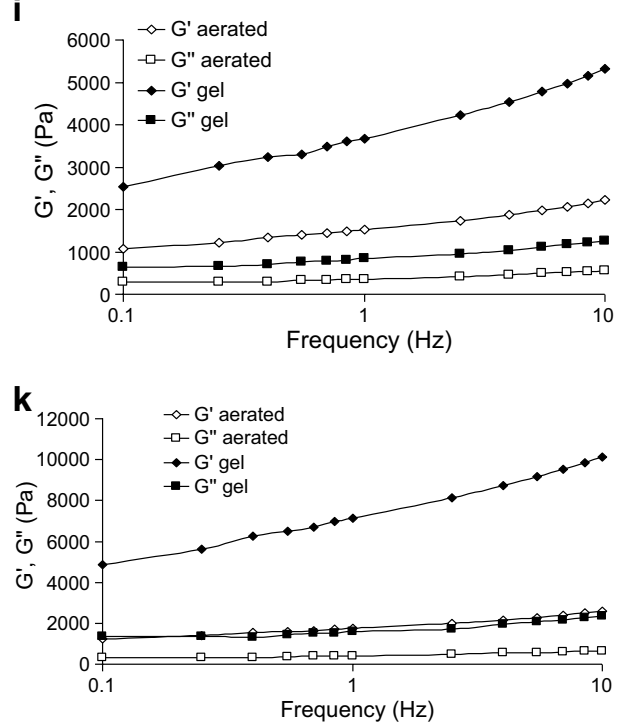

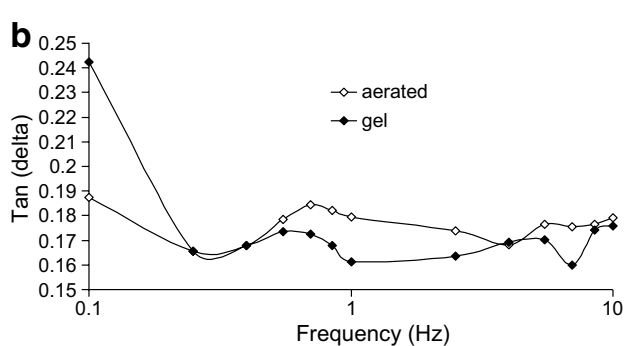

d

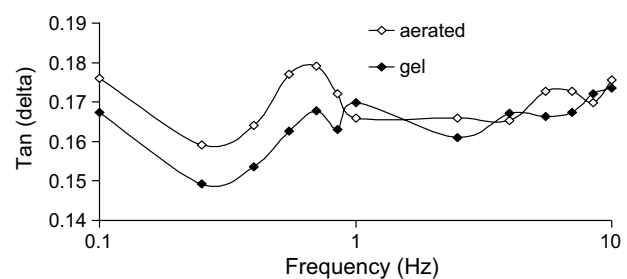

f

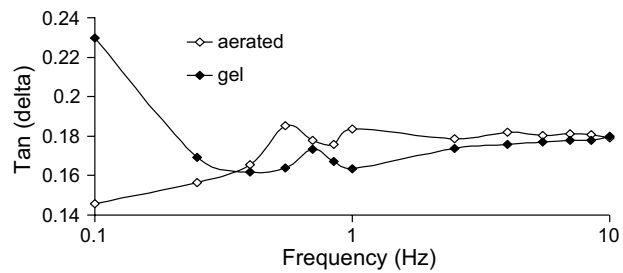

h

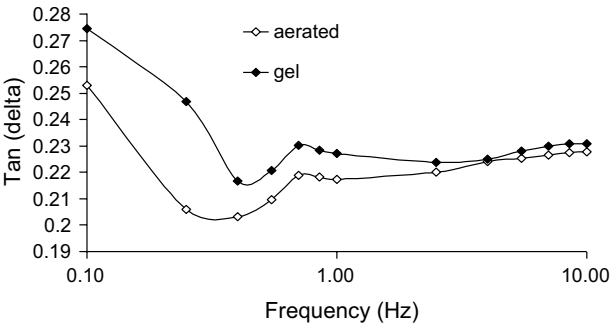

j

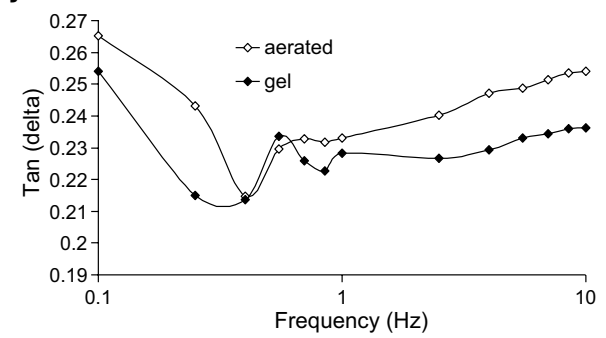

I

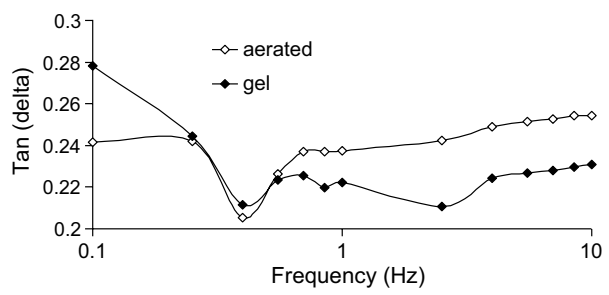


obtaining aerated gels with the highest viscosity and hardness (Fig. 1). At lower calcium concentration, gel is too weak and at larger calcium concentration its structure is difficult to re-heal when the disruptive forces at the aeration are removed. The aerated one obtained at $20 \mathrm{mM} \mathrm{Ca}^{2+}$ is weaker than non-aerated gel as the structure was broken, but the aerated gels created after gel reversibility are more elastic than the non-aerated ones. It can be caused by better mixing of the calcium ions in the protein solution caused by the aeration/mixing process. The same process is probably responsible for larger moduli values observed for the aerated gel at smaller calcium concentrations $(5-10 \mathrm{mM})$ (Fig. 2a, c). For the higher concentration of calcium ions $(25-30 \mathrm{mM})$, aerated gels were characterized by lower values of the moduli and the tangent of the phase angle was larger for the aerated gels indication more viscous character the non-aerated gels (Fig. 2g-1).

\section{Microstructure}

Figure 3 shows the influence of calcium ions concentration on the microstructure of aerated gels obtained at $6 \%$ protein concentration. Increased ions concentration causes higher aggregation of protein matrix as protein aggregates with larger size are observed. At higher calcium concentration less smooth microstructure is observed at the interface between the gel and air. The increased aggregation of the microstructure with the increasing $\mathrm{Ca}^{2+}$ ions concentration was observed for the heat-induced egg white gels by Croguennec et al. [18].

\section{Turbiscan measurements}

The Turbiscan backscattering and transmission curves were obtained for the aerated egg white protein gels produced from $6 \%$ pre-heated protein dispersions and induced by $\mathrm{Ca}^{2+}$ ions at different concentrations. An increase in the calcium concentration from 5 to $30 \mathrm{mM}$ caused an increase in an average bubble size (Fig. 4). In some previous research, Tomczyńska-Mleko et al. [24] found for the aerated gels that the average bubble size increased by about 3-4 times at higher ion concentration. This behavior was probably caused by changes in the microstructure of the gel matrix. Higher ion concentration causes formation of more particulate gels with a larger diameter. Large aggregates form a coarser structure capable of holding larger bubbles. More particulate gels obtained at higher calcium concentration are stronger as higher hardness of the aerated gels is noted for higher calcium concentration up to $20 \mathrm{mM}$ (Fig. 1). At 25 and $30 \mathrm{mM}$ softer aerated gels are obtained as strong particulate gels could not re-heal after
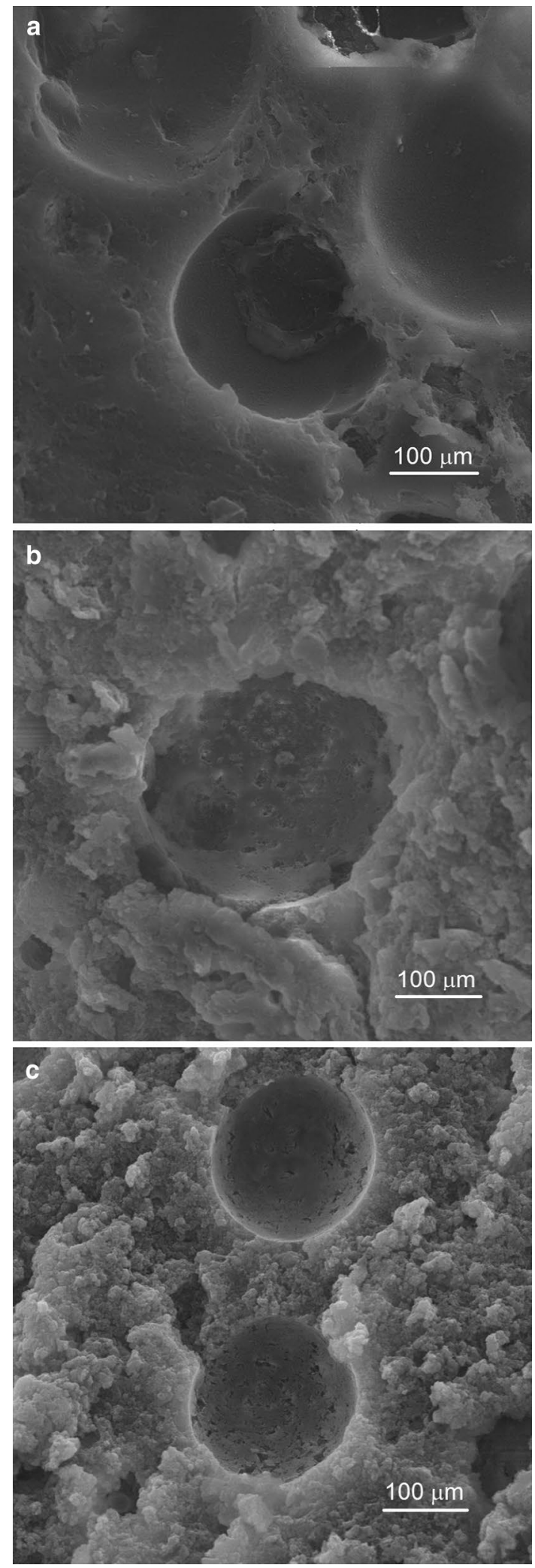

Fig. 3 Aerated egg white protein gels obtained from $6 \%$ protein preheated solution induced by $10(\mathbf{a}), 20(\mathbf{b})$ or $30(\mathbf{c}) \mathrm{mM} \mathrm{Ca}^{2+}$ 


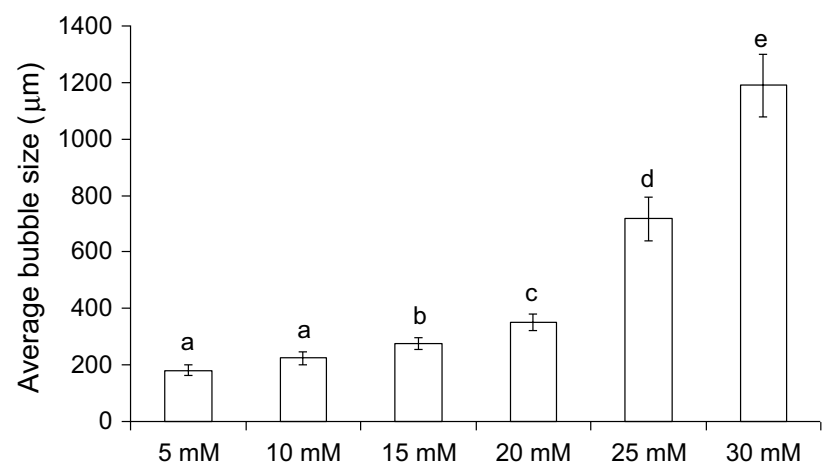

Fig. 4 Influence of calcium concentration on the average air bubble size of the aerated gels

the aeration process destroying their microstructure. Zuniga and Aguilera [25] found bubble size distributions of airfilled gels shifted toward larger diameters when the gassed gelatin gels were produced at higher protein concentration and similar results were found for nitrogen and helium. Katsman [26] found strong positive correlation between the size of methane bubbles and the fine-grained muddy aquatic sediments with the sediment fracture toughness. Bubbles formed in the weaker sediments were smaller, less inflated, and were characterized by the larger surfaceto-volume ratio [26]. For the gels produced in the current research, higher calcium concentration did not cause a permanent increase in the maximum puncture force (Fig. 1) because at higher concentration it was difficult for the aerated gels to re-heal. Still the structure of the gel at the gel/ air interface was stronger, and it was possible to hold larger air bubbles with larger interior pressure. The problem of the bubble size in the ion-induced gels is more complicated than that of aeration of a gel matrix. Salt solution is added to the pre-heated protein dispersion, and the aeration process is performed. At the same time ions cause aggregation of protein molecules, viscosity of the dispersion increases and a "liquid gel" is formed. It was monitored in the previous research concerning magnesium ion-induced gels [27]. So the main difference between the aeration of ion-induced gels and the steady-matrix gels is, the former have a continuously changing microstructure. Even after aeration, the samples were stored for $20 \mathrm{~h}$ and there were still changes in the texture and the process of gel aging was still ongoing.

\section{Digestion of the gels in an artificial stomach}

Aerated egg white protein gels were used as matrices for the release of calcium ions (Fig. 5). Ritger and Peppas [28] regarded release of an active substance from a polymer as combination of diffusion of the active ingredient from the matrix and the particle transport through the polymer

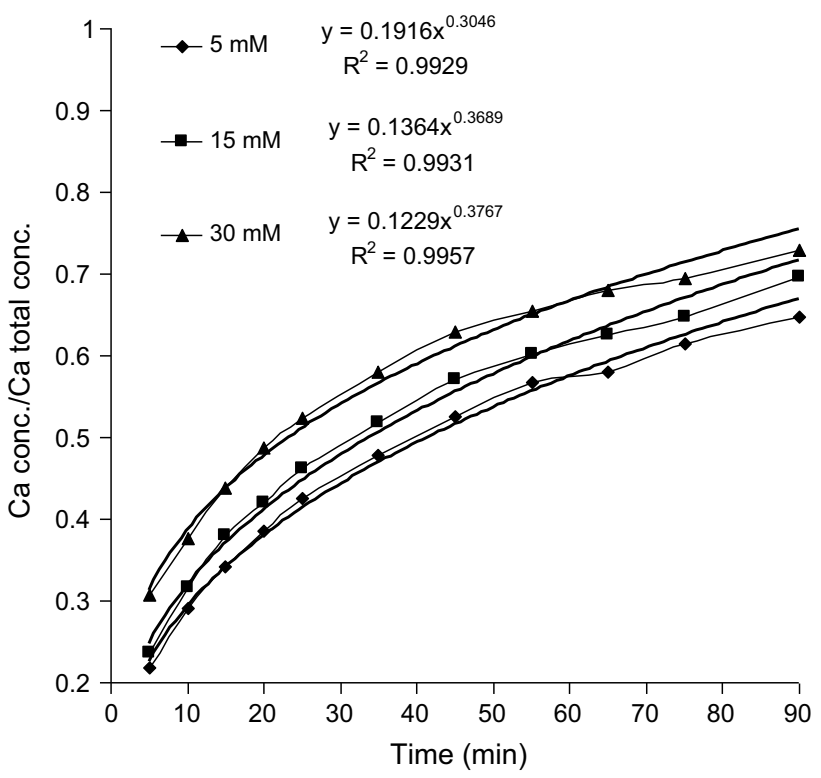

Fig. 5 Digestion in an artificial stomach of $6 \%$ protein aerated gels induced at different calcium concentration

chains. They proposed a semi-empirical equation describing the process of active substance release, which consists of these two phenomena:

$M_{t} / M_{\infty}=k t^{n}$

where $M_{t}$ mass of an active substance released after time $t, M_{\infty}$ total mass of an active substance, $t$ time, $k$ kinetic constant, $n$ exponent.

The coefficient $k$ is a constant characteristic for the polymer matrix, and $\mathrm{n}$ is a coefficient characteristic of the type of release mechanism. The value of " $n$ " depends on the shape of the samples and for thin films, cylinders, cubes and spheres it is $0.5,0.45,0.44$ and 0.43 for the mechanism of diffusion and 1.0, 0.89, 0.87 and 0.85 for the transport mechanism through the polymer chains [29]. Figure 5 presents the curves showing the release of the calcium ions used as an active ingredient in the range of 0-60\% of the total ions concentration as proposed by Kosmidis et al. [29]. The curve was analyzed using the nonlinear regression analysis, and the parameters " $k$ " and " $n$ " from the power law equations were obtained. The value " $n$ " increased with the increasing calcium concentration and was in the range $0.30-38$. It means that the release occurred by the Fickian diffusion through the swelling matrix, and it was faster for the gels with higher calcium concentration. Yang et al. [30] studied the release of egg white albumen from chitosan-calcium-gellan gum beads and fitted it to the Korsmeyer-Peppas model. In this research the release also occurred by the diffusion process as the value of the coefficient " $n$ " was 0.43 . 
Fig. 6 Correlations between the surface roughness coefficients and " $n$ " coefficient from the Ritger and Peppas equation (inside correlation between the quadratic mean of the surface roughness $\left(R_{q}\right)$ and the maximum roughness height $\left(R_{t}\right)$ for the aerated gels induced by different calcium concentrations)

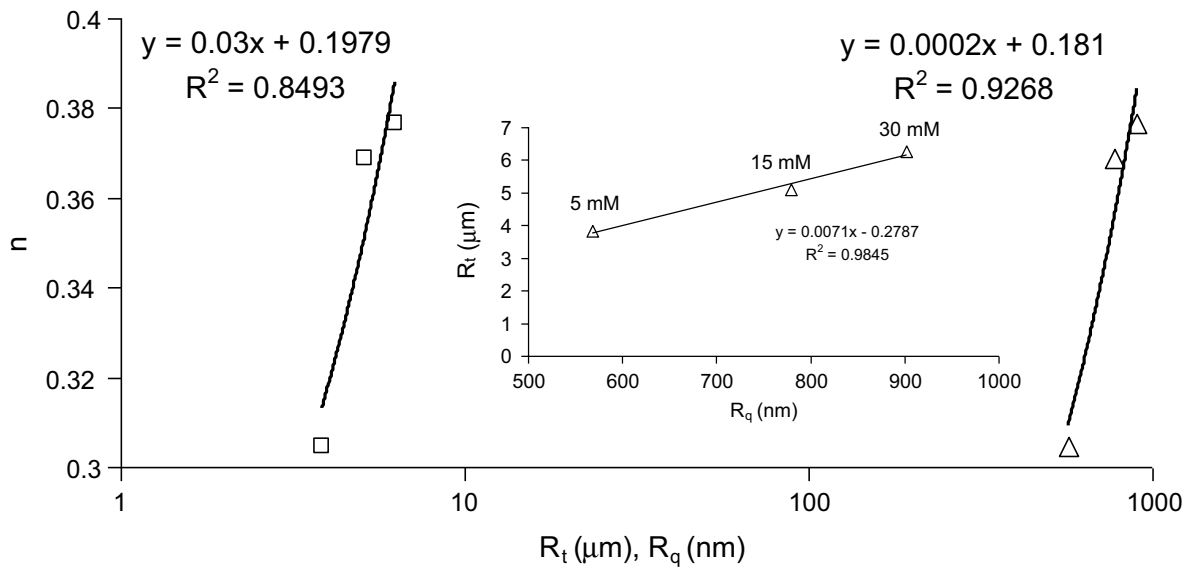

\section{Surface roughness}

Aerated gels surface used for hydrolysis experiments was observed by an optical profilometer, and the results are presented in Fig. 6. An increase in calcium concentration caused an increase in surface roughness. There is a linear correlation between the quadratic mean of the surface roughness $\left(R_{q}\right)$ and the maximum roughness height $\left(R_{t}\right)\left(R^{2}=0.98\right)$ (chart inside). Similar correlation was observed for the non-aerated egg white gels [19]. Chen et al. [31] observed that whey protein gel obtained without the sodium ions addition had a very smooth surface, with $R_{q}$ and $R_{a}$ (arithmetic average of the collected roughness points) of 0.20 and $0.18 \mu \mathrm{m}$, respectively. At an increased $200 \mathrm{mM} \mathrm{NaCl}$ concentration, a much rougher surface with high $R_{q}$ and $R_{a}(2.39$ and $1.91 \mu \mathrm{m}$, respectively) was observed. Figure 6 shows the correlations between the quadratic mean of the surface roughness and " $n$ " coefficient from the Ritger and Peppas equation and between the maximum roughness height and " $n$ ". There is a linear correlation between these parameters. The increased calcium concentration makes the gel microstructure more particulate and the surface rougher, which enables faster proteolysis of the gel in an artificial stomach and faster diffusion of calcium ions (higher " $n$ " value).

\section{Conclusions}

Low-mineral egg white albumin isolate is a good material for ions-induced gelation. By simultaneous gelation and mixing, it is possible to obtain aerated gels with various properties. Increased ions concentration causes higher aggregation of protein matrix and less smooth microstructure of the interface between the gel and air. There is an optimal concentration of calcium ions at which the aerated gels are the strongest. An increase in calcium concentration causes an increase in an average bubble size. The release of calcium ions from the aerated gels occurs by the Fickian diffusion through the swelling matrix, and it is faster for the gels with higher calcium concentration. More particulate gels with a rougher surface are more susceptible for faster proteolysis of the gel in an artificial stomach and faster diffusion of calcium ions. Aerated egg white gels could be applied as floating carriers of drugs used for stomach inflammation and ulcers.

\section{Compliance with ethical standards}

Conflict of interest The authors declare that they have no conflict of interest.

Compliance with ethics requirements This article does not contain any studies with human or animal subjects.

Open Access This article is distributed under the terms of the Creative Commons Attribution 4.0 International License (http://creativecommons.org/licenses/by/4.0/), which permits unrestricted use, distribution, and reproduction in any medium, provided you give appropriate credit to the original author(s) and the source, provide a link to the Creative Commons license, and indicate if changes were made.

\section{References}

1. Miguel M, Asuncion MM, López-Fandiño R, Ramos M (2005) Comparative study of egg white proteins from different species by chromatographic and electrophoretic methods. Eur Food Res Technol 221(3):542-546

2. Yang L, Alexandridis $P$ (2000) Physicochemical aspects of drug delivery and release from polymer-based colloids. Curr Opin Colloid In Sci 5(1-2):132-143

3. Lin CC, Metters AT (2006) Hydrogels in controlled release formulations: network design and mathematical modeling. Adv Drug Deliv Rev 58(12-13):1379-1408

4. Burey P, Bhandari BR, Howes T, Gidley MJ (2008) Hydrocolloid gel particles: formation, characterization, and application. Crit Rev Food Sci Nutr 48(5):361-377

5. Su Y, Dong Y, Niu F, Wang C, Liu Y, Yang Y (2015) Study on the gel properties and secondary structure of soybean protein isolate/egg white composite gels. Eur Food Res Technol 240(2):367-378 
6. Lin S, Ionescu C, Pike KJ, Smith ME, Jones JR (2009) Nanostructure evolution and calcium distribution in sol-gel derived bioactive glass. J Mater Chem 19(9):1276-1282

7. Trafton A (2009) New gel permits controlled drug delivery. MIT Techn Talk 3:4

8. Rajinikanth PS, Mishra B (2008) Floating in situ gelling system of acetohydroxamic acid for clearance of $\mathrm{H}$. pylori. Drug Dev Ind Pharm 34(6):577-587

9. Tomczyńska-Mleko M (2012) Ion induced gelation of whey proteins as a new method to produce foamed globular protein gels. Milchwissenschaft 67(4):443-446

10. Tomczyńska-Mleko M, Mleko S (2014) Whey protein aerated gels as matrices for controlled mineral release in simulated gastric conditions. Food Res Int 62(8):91-97

11. Mleko S (1999) Effect of protein concentration on whey protein gels obtained by a two-stage heating process. Eur Food Res Technol 209(6):389-392

12. Goh KS, Bhat R, Karim AA (2009) Probing the sol-gel transition of egg white proteins by pulsed-NMR method. Eur Food Res Technol 228(3):367-371

13. Martin AH, de Jong GAH (2012) Impact of protein pre-treatment conditions on the iron encapsulation efficiency of whey protein cold-set gel particles. Eur Food Res Technol 234(6):995-1003

14. Foegeding EA, Barbut S (1993) $\mathrm{Ca}^{2+}$-Induced gelation of preheated whey protein isolate. J Food Sci 58(4):867-871

15. Hongsprabhas P, Barbut S (1997) Protein and salt effects on $\mathrm{Ca}^{2+}$-induced cold gelation of whey protein isolate. J Food Sci 62(2):382-385

16. Bryant CM, McClements DJ (2000) Influence of $\mathrm{NaCl}$ and $\mathrm{CaCl}_{2}$ on cold set gelation of heat-denatured whey protein. $\mathrm{J}$ Food Sci 65(5):801-804

17. Holt DL, Watson MA, Dill CW, Alford ES, Edwards RL, Diehl KC, Gardner FA (1984) Correlation of the rheological behavior of egg albumen to temperature, $\mathrm{pH}$, and $\mathrm{NaCl}$ concentration. $\mathrm{J}$ Food Sci 49(1):137-141

18. Croguennec T, Nau F, Brule G (2002) Influence of $\mathrm{pH}$ and salts on egg white gelation. J Food Sci 67(2):608-614

19. Tomczyńska-Mleko M, Nishinari K, Handa A (2014) Ca-induced egg white protein gels with various microstructure. Food Sci Technol Res 20(6):1207-1212
20. Bubni Z, Urleb U, Kreft K, Veber M (2011) The application of atomic absorption spectrometry for the determination of residual active pharmaceutical ingredients in cleaning validation samples. Drug Dev Ind Pharm 37(3):281-289

21. da Silva MV, Delgado JMPQ, Gonzales MP (2010) Impact of $\mathrm{Mg}^{2+}$ and tara gum concentrations on flow and textural properties of WPI solutions and cold-set gels. Int J Food Prop 13(5):972-982

22. Tomczyńska-Mleko M, Wesołowska-Trojanowska M, Grzegory P, Mleko S, Ozimek L (2012) Reversibility of whey protein concentrate/locus bean gum gels. Milchwissenschaft 67(3):311-314

23. Toker OS, Dogan M, Caniyilmaz E, Ersoz NB, Kaya Y (2013) The effects of different gums and their interactions on the rheological properties of a dairy dessert: a mixture design approach. Food Bioprocess Technol 6(4):896-908

24. Tomczyńska-Mleko M, Terpiłowski K, Mleko S, Kwiatkowski C, Kawecka-Radomska M (2015) Surface properties of aerated ion-induced whey protein gels. Food Biophys 10(3):273-281

25. Zúñiga RN, Aguilera JM (2009) Structure-fracture relationships in gas-filled gelatin gels. Food Hydrocolloids 23(5):1351-1357

26. Katsman R (2015) Correlation of shape and size of methane bubbles in fine-grained muddy aquatic sediments with sediment fracture toughness. J Struct Geol 70(1):56-64

27. Tomczyńska-Mleko M (2015) Development of a new product: egg white albumen gels with differentiated magnesium release. $\mathbf{J}$ Elem 20(2):463-475

28. Ritger P, Peppas N (1987) A simple equation for description of solute release. II. Fickian and anomalous release from swellable devices. J Control Release 5(1):37-42

29. Kosmidis K, Rinaki E, Argyrakis P, Macheras P (2003) Analysis of case II drug transport with radial and axial release from cylinders. Int J Pharm 254(2):183-188

30. Yang F, Xia S, Tan C, Zhang X (2013) Preparation and evaluation of chitosan-calcium-gellan gum beads for controlled release of protein. Eur Food Res Technol 237(4):467-479

31. Chen J, Moschakis T, Pugnaloni LA (2006) Surface topography of heat-set whey protein gels by confocal laser scanning microscopy. Food Hydrocolloid 20(4):468-474 